\title{
Sutureless Vitrectomy
}

\author{
G.W. Aylward \\ Moorfields Eye Hospital, London, UK
}

\section{Key Words}

Pars plana vitrectomy $\cdot$ Sutureless incisions $\cdot 20$ gauge $\cdot$

25 gauge $\cdot 23$ gauge $\cdot$ Transconjunctival vitrectomy

\begin{abstract}
The introduction of pars plana vitrectomy was a revolution in ophthalmic surgery which allowed successful treatment of many previously untreatable conditions. After rapid early technical development, 3-port 20-gauge vitrectomy became established as the norm. Recent years have seen the introduction of new and innovative systems for performing vitrectomy without the need for sutures. This article describes the history of sutureless vitrectomy, and reviews the literature addressing the advantages and disadvantages of each technique.

Copyright $\odot 2010$ S. Karger AG, Base
\end{abstract}

\section{Introduction}

The history of ophthalmic surgery is a long one, with operations for cataract being reported from ancient Babylon and India many thousands of years ago. However, for the vast majority of that time, the vitreous remained a "no man's land" where the surgeon only ventured by accident, or misguided intention. Minor forays into vitreous surgery were reported, most notably the identification and division of vitreous strands to treat macular oedema fol- lowing intracapsular cataract surgery by Iliff [1]. Major surgery on the vitreous for opacity was not seriously attempted until the early 1970s, when David Kasner [2] used a sponge and scissor 'open sky' technique to remove an opaque vitreous body in a patient with amyloid. Problems with that technique included lack of control of intraocular pressure (IOP), and the general issue of removing a gel structure which applied remote traction on the retina.

Both these problems were addressed by the invention of closed intraocular microsurgery by Machemer [3]. Working in his garage at home in Miami, he devised a method of safely removing vitreous gel through a relatively small opening. The instrument was multifunction$\mathrm{al}$, and required a sclerotomy of $1.5 \mathrm{~mm}$ diameter. The possibility of making the sclerotomy even smaller was recognised by O'Malley and Heintz [4], who separated the functions of cutting, infusion and illumination, thereby requiring three 20 -gauge $(20 \mathrm{~g})$ sclerotomies. Further refinements followed rapidly, and the standard procedure of $20 \mathrm{~g}$ pars plana vitrectomy (PPV) was established as a routine component of ophthalmic surgery. Subsequent interest focussed on developing additional $20 \mathrm{~g}$ instruments to achieve further surgical goals once the vitreous had been removed, such as various types of forceps, scissors and flute needles. The practice of PPV using $20 \mathrm{~g}$ vitrectomy instruments through the sclera, following reflection of the conjunctiva, was the 'standard of care' for nearly 3 decades.

\section{KARGER}

Fax +4161306 1234 E-Mail karger@karger.ch www.karger.com

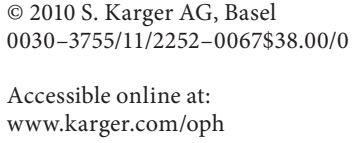

Mr. G.W. Aylward

Moorfields Eye Hospital

162 City Road

London EC1V 2PD (UK)

Tel./Fax +44 207566 2039, E-Mail bill.aylward@moorfields.nhs.uk 


\section{Towards Sutureless $\mathbf{2 0 g}$ Vitrectomy}

A number of problems with 20g PPV were identified, including iatrogenic retinal breaks, particularly those associated with the sclerotomies (entry site breaks). The risk of entry site breaks was considered to be related to the repeated entry and exit of instruments through the sclerostomies, and consequent damage to the vitreous base. In an attempt to reduce this risk, Machemer and Hickingbotham [5] introduced a system of cannulas which were inserted through the sclerostomies for the duration of the case. These allowed repeated insertion and removal of $20 \mathrm{~g}$ instruments, while minimising trauma to the vitreous base.

The need to suture the sclerostomies was considered to be the time-consuming part of the surgical procedure, so a number of suggestions were made to reduce the requirement for suturing. Hilton [6] described a sutureless self-retaining infusion cannula in 1985, and a modification of this idea was reported in 1990 [7].

In 1996, Chen [8] described a method of producing self-sealing sclerotomies. The technique involved creating a shallow scleral pocket (posteriorly to anteriorly), with entry into the vitreous at the top of the pocket. In a series of 50 patients, no complications were encountered; the wounds were self-sealing and required no scleral sutures in 47 of the 50 patients. The author recommended the technique firstly on the basis of avoiding sutures, and secondly because of the improved control over intraoperative ocular pressure. No claims were made of faster rehabilitation or increased patient comfort, presumably because conjunctival sutures were still required and these were the primary cause of any postoperative patient discomfort.

Other authors reported problems with the technique, including difficult access in patients with narrow palpebral fissures, wound leakage and (more seriously) re-operation to suture wounds associated with recurrent haemorrhage [9]. In another series of 50 patients, a sclerostomy required suturing at the end of the operation in $35(23.3 \%)$ of the 150 sclerostomies [10].

Several modifications of this technique were proposed. Kwok et al. [11] rotated the pocket by $90^{\circ}$ to reduce the risk of damage to the lens from the anterior entry incision. No complications were reported in a series of 25 patients, though $11 \%$ of the sclerostomies required suturing to avoid leakage. The circumferential technique was also investigated by Jackson [12], who reported complications including wound extension, flap dehiscence, and vitreous and retinal incarceration in a series of $30 \mathrm{pa}-$ tients. The author sutured the flap at the end of the procedure to avoid the late wound leakage reported earlier, thereby obviating one of the key stated advantages of the technique.

Assi et al. [13] advised rotating the pocket an additional $90^{\circ}$, so that the pocket was accessed anteriorly. They also used a pocket knife to fashion a pouch, and reported on 50 sclerotomies in 25 eyes. Suturing was required in 3 cases, and there was a 'limited choroidal haemorrhage' associated with introduction of the infusion cannula in 1 case. There were also 2 entry site retinal tears, but no post-operative complications related to the technique.

Supporters of sutureless sclerotomies claimed that the chief advantages were reduced operative time, less risk of peri-operative hypotony on removal of instruments, and less post-operative inflammation. However, these advantages were unproven, and none of the reported techniques gained significant popularity, probably because there still remained the requirement to suture the conjunctiva.

\section{5g Vitrectomy}

In 2002, a radically new method of carrying out vitrectomy was described which used newly designed $25 \mathrm{~g}$ instruments and a transconjunctival approach, thereby removing the need for either scleral or conjunctival sutures [14]. The technique also re-introduced the concept of the pars plana cannula, but with 2 significant differences. Firstly the internal diameter of the cannula was only $0.5 \mathrm{~mm}$, and secondly, the conjunctiva was not reflected first, the cannula being inserted through both the conjunctiva and sclera. At the end of surgery, the cannulae could be simply removed, leaving a wound sufficiently small to require no sutures. In a companion paper, the authors described 35 eyes which had undergone $25 \mathrm{~g}$ transconjunctival sutureless vitrectomy (TSV) for relatively straightforward conditions, such as macular hole and epiretinal membrane [15]. None of the eyes required any sutures at the end of surgery, and no significant complications were reported. Five eyes had IOP $<10 \mathrm{~mm} \mathrm{Hg}$ on the first day, but no active management was required, and the pressure had increased to normal by 1 week. The authors claimed that the new system offered faster surgery, improved post-operative comfort and more rapid patient recovery.

The technique was originally used for straightforward conditions, such as epiretinal membrane and macular hole $[16,17]$, but as experience has been gained and as bet- 
ter instruments have been introduced, the indications have broadened to include more complex conditions, such as diabetic traction detachment, rhegmatogenous retinal detachment and silicone oil cases $[18,19]$.

The new $25 \mathrm{~g}$ system increased in popularity, though many surgeons encountered a number of operative difficulties. The cannulas are introduced using a trocar system, and early versions were occasionally insufficiently sharp to pass through the conjunctiva and sclera easily. A consequence of the smaller gauge was reduced rigidity of the instruments, which produced difficulties in rotating the globe during surgery. This was accompanied by more difficult access to the peripheral vitreous, and as a consequence, more vitreous was often left in the eye compared to $20 \mathrm{~g}$ vitrectomy. The smaller bore of the infusion and cutter resulted in reduced fluid flow, which meant that the duration of the vitrectomy was longer than with $20 \mathrm{~g}$ surgery [20]. In addition, blockage of the cutter with fibrous tissue and breakage of the narrow instruments were reported [22].

\section{Endophthalmitis}

Endophthalmitis is a serious complication of intraocular surgery, but is generally acknowledged to be less common following vitrectomy than other forms of intraocular surgery. For example, the incidence of endophthalmitis following $20 \mathrm{~g}$ vitrectomy was $0.07 \%$ in one 10 -year survey [22]. In a series reported from the Bascom Palmer Eye Institute, the rate of endophthalmitis following $20 \mathrm{~g}$ vitrectomy was only $0.039 \%(6 / 15,326$ eyes) [23]. These low rates mean that most vitreoretinal surgeons can expect to see only a small number of cases in the course of their career.

The first reported case of endophthalmitis following $25 \mathrm{~g}$ surgery was published in 2005 [24]. The authors speculated that the lack of wound closure and the lower rate of flow of sterile fluid through the globe might contribute to an increased risk in $25 \mathrm{~g}$ surgery. A number of other case reports followed, but more accurate estimates of the risk of endophthalmitis did not emerge until larger series were presented.

A very large series of cases reported from the Wills Eye Institute showed an endophthalmitis rate of $0.23 \%$ $(7 / 3,103$ eyes) for $25 \mathrm{~g}$ vitrectomy compared with only $0.018 \%$ (1/5,498 eyes) for $20 \mathrm{~g}$ vitrectomy, representing a 12 -fold increased risk for $25 \mathrm{~g}$ vitrectomy [25]. An accompanying leader to this article pointed out potential problems with the study, including its retrospective nature,
Table 1. Cases of endophthalmitis following 25-gauge vitrectomy

\begin{tabular}{|c|c|c|c|}
\hline First author & Cases & Organism & Final VA \\
\hline Taylor [24] & 1 & culture negative & $20 / 30$ \\
\hline Taban [27] & 1 & culture negative & $20 / 60$ \\
\hline Acar [31] & 1 & $\begin{array}{l}\text { coagulase-negative } \\
\text { staphylococci }\end{array}$ & $20 / 63$ \\
\hline Kunimoto [25] & 7 & $\mathrm{n} / \mathrm{a}$ & $20 / 50$ to NLP \\
\hline Scott [27] & 11 & $\begin{array}{l}\text { coagulase-negative } \\
\text { staphylococci in } 6 ; \\
\text { enterococcus in } 1\end{array}$ & $20 / 63$ to $20 / 400$ \\
\hline
\end{tabular}

$\mathrm{NLP}=$ No light perception

and the possibility that the use of intravitreal triamcinolone might have caused some cases of apparent endophthalmitis. It advised caution in interpreting the data, and called for a prospective evaluation [26]. Another large retrospective series of a total of 7,682 cases reported an even higher incidence of endophthalmitis in $25 \mathrm{~g}$ cases of $1 / 119$ patients $(0.84 \%)$ compared to $1 / 3,188(0.03 \%)$ for $20 \mathrm{~g}$ cases [27].

However, other more recent series have not shown a difference. A series of 6,935 patients found only a single case of endophthalmitis in each group of $20 \mathrm{~g}$ and $25 \mathrm{~g}$ patients [28]. The low rate in this series may be related to the authors' practice of admitting all vitrectomy patients for intravenous infusion of new-generation fluoroquinolones. The surgeons in this latter study also emphasised the importance of conjunctival irrigation, ensuring sclerotomy closure and removal of peripheral vitreous as important preventative measures. In another large retrospective series from a single institution, there were similar rates of endophthalmitis between $25 \mathrm{~g}(1 / 1,906$ or $0.053 \%)$, and $20 \mathrm{~g}(2 / 2,642$ or $0.076 \%)$ patients. The authors of this study had modified the originally described technique in several respects, including angled incisions, deliberate misalignment of the conjunctival and scleral incisions, and checking for leaking incisions at the end of surgery (and suturing them if necessary) [29].

The causative organisms in the reported case are summarised in table 1 . In the majority of cases, the organisms are conjunctival commensals, which is compatible with the concept of the transconjunctival route or the open conjunctival wounds being a risk factor. The visual outcome in these cases was variable, with some patients making a complete recovery, but others having very poor outcomes. 
The weight of available evidence seems to suggest that the $25 \mathrm{~g}$ vitrectomy is associated with an increased risk of endophthalmitis when compared to $20 \mathrm{~g}$ vitrectomy, and that this can lead to a poor visual outcome. The absolute risk remains low, and it is possible that the risk can be reduced by modifications in the technique, such as conjunctival irrigation with iodine, better wound construction, ensuring wound closure and prophylactic antibiotics [30]. However, only a large scale prospective trial will be able to definitively show whether these measures are effective.

\section{Wound Leakage}

A significant concern with all sutureless systems is hypotony, and this is directly related to leaking wounds. In the original description of $25 \mathrm{~g}$ TSV, an IOP $<8 \mathrm{~mm} \mathrm{Hg}$ was observed on the first post-operative day in 4 of 35 eyes (11\%), although normal pressures were reported at 1 week in all cases [15]. Other authors have reported higher rates, and in one recent series of 111 eyes following $25 \mathrm{~g}$ vitrectomy with straight incisions, the hypotony rate (defined as an IOP $<8 \mathrm{~mm} \mathrm{Hg}$ ) at $2 \mathrm{~h}$ after the operation was $26.12 \%$, decreasing to $17.11 \%$ on day 1 , and to $8.10 \%$ at the end of week 1 [32].

In the vast majority of reported cases, the hypotony usually resolves without sequelae, although the eye is theoretically at higher risk of serious complications - such as hypotony retinopathy, choroidal effusions and choroidal haemorrhage - while the low pressure persists. A rate of choroidal effusion of $3.8 \%$ was reported in one series of 140 eyes on day 1 , but all cases had resolved without additional treatment by the end of the first post-operative week [17]. A similar incidence was reported by Lommatzsch et al. [33], with 9 out of 329 eyes undergoing surgery for epiretinal membrane developing choroidal effusions, and in this series the leaking wounds were all treated by suturing. Retinopathy was reported in 2 cases with precipitous drops in IOP due to post-operative hypotony, in eyes which had raised IOP prior to surgery [34]. The risk of both hypotony and choroidal effusions may be higher in eyes which have had a previous vitrectomy, perhaps because of reduced internal plugging of the ports by residual vitreous [35].

Another potential complication of leaking wounds is that they allow ingress of any subconjunctival drugs which may be administered. At least 1 case of macular infarction associated with a post-operative subconjunctival injection of gentamicin gas been reported [36].
Degrees of leakage insufficient to cause hypotony may nevertheless be associated with conjunctival bleb formation. An ultrasound biomicroscopy (UBM) study in direct and oblique sclerotomy incisions by $25 \mathrm{~g}$ vitrectomy showed that conjunctival blebs developed in over $64 \%$ of direct sclerotomies and $25 \%$ of oblique sclerotomies, but they all resolved spontaneously by day 15 after surgery [37]. In a similar study, Riemann et al. [38] identified a small subconjunctival bleb in 2 out of 35 eyes after $25 \mathrm{~g}$ vitrectomy.

A number of approaches have been taken to address the issue of wound leakage. It is likely that the surface tension of an intraocular gas bubble may reduce fluid flow through the sclerotomies, and in one comparative series, the rate of hypotony was less in gas-filled eyes than in those left with fluid [39]. Some success has been obtained by the use of tissue glue to close any leaking wounds at the end of surgery [40].

Other surgeons have suggested modifications of the wound construction in order to reduce leakage. For example, the use of oblique sclerotomies eliminated wound leakage in all sclerotomies in 12 patients having $25 \mathrm{~g}$ vitrectomy [41]. Hsu et al. [42] found lower rates of hypotony on the first post-operative day as compared with perpendicular incisions. A significant reduction in the incidence of hypotony to $1 \%$ was observed when a scleral tunnel was used in combination with $25 \mathrm{~g}$ cannulae [43, 44]. The function and benefit of such incision construction has been shown experimentally in animal models. In a study using Trypan blue to evaluate wound leakage in an animal model, leakage was noted in $10.8 \%$ of straight wounds but only $5.7 \%$ of angled incisions, with no difference between $25 \mathrm{~g}$ and $23 \mathrm{~g}$ incisions [44].

\section{Retinal Tears and Detachment}

It had been hoped that the introduction of cannulas might reduce the incidence of entry site breaks and subsequent retinal detachment, but it remains unclear whether this potential advantage will be realised. The available evidence does not indicate any significant difference between $25 \mathrm{~g}$ and $20 \mathrm{~g}$ vitrectomy in the post-operative rates of retinal tears and detachment. In a series of 347 eyes receiving either $20 \mathrm{~g}$ or $25 \mathrm{~g}$ vitrectomy for epiretinal membranes or macular holes, there were 14 (6.4\%) of 219 eyes in the $20 \mathrm{~g}$ group with retinal breaks compared to only 4 (3.1\%) of 128 eyes in the $25 \mathrm{~g}$ group. However, this difference was not statistically significant [45]. Disappointingly, other surgeons have reported high- 
er rates of retinal tear formation following $25 \mathrm{~g}$ vitrectomy, with one series reporting 4 cases out of 75 (5.3\%), many of them in patients undergoing surgery for macula hole [46]. A more recent series of 177 operations for macular pucker or macular hole reported iatrogenic retinal breaks in $15.8 \%$ of cases [47].

The reported rate of retinal detachment following $20 \mathrm{~g}$ vitrectomy is of the order of $1-2 \%$ for routine cases, such as macular holes [48]. Table 2 summarises reported rates of post-operative detachment following $25 \mathrm{~g}$ vitrectomy, from which it is clear that the rates are not significantly different.

\section{Post-Operative Pain}

One of the key stated advantages of $25 \mathrm{~g}$ TSV is reduced post-operative pain, though this has only rarely been examined scientifically. In a non-randomised study of 46 patients having surgery for epiretinal membranes, a scoring system was devised to assess the combination of pain, discomfort, lacrimation and photophobia with total range of $1-13$. The mean score in the $20 \mathrm{~g}$ group was 4.2 compared with 1.9 in the $25 \mathrm{~g}$ group, and this difference was statistically significant [50]. In the first prospective randomised clinical trial examining post-operative pain $25 \mathrm{~g}$ and $20 \mathrm{~g}$ vitrectomy in 60 patients, the authors assessed postoperative pain using a simple scoring scale from grade 1 (no pain) to grade 4 (severe pain). They reported a significant reduction in post-operative discomfort in the $25 \mathrm{~g}$ group, but no detailed results were given [20]. A small and more recent randomised trial looking specifically at patient comfort confirmed that $25 \mathrm{~g}$ was more comfortable than $20 \mathrm{~g}$ vitrectomy, but that the level of pain in either group was mild. Only $7.2 \%$ of the pain scores were greater than 1 out of 10 in all patients, and very few required oral analgesia [51].

\section{Astigmatism}

One of the stated advantages of sutureless vitrectomy is that it is associated with less post-operative astigmatism, though this complication has only rarely been studied in the past. The first reported study examined 67 eyes of 64 patients undergoing $20 \mathrm{~g}$ vitrectomy, and found an average of $1 \mathrm{dpt}$ of against-the-rule astigmatism. This had regressed to less than $0.15 \mathrm{dpt}$ by the 7 th postoperative week, and the authors concluded that vitrectomy was not associated with clinically significant astigmatism [52]. A
Table 2. Rate of post-operative retinal detachment following $25 \mathrm{~g}$ vitrectomy

\begin{tabular}{lll}
\hline First author & \multicolumn{2}{l}{ Post-operative RRD rate } \\
\cline { 2 - 3 } & $\mathrm{n}$ & $\%$ \\
\hline Fuji [15] & $1 / 35$ & 2.9 \\
Ibarra [16] & $1 / 45$ & 2.2 \\
Byeon [49] & $3 / 50$ & 6 \\
Lommatzsch [32] & $7 / 329$ & 2.1 \\
\hline
\end{tabular}

later study of 44 patients found a mean of $3.65 \mathrm{dpt}$, reducing to $0.40 \mathrm{dpt}$ after 3 months [53]. The authors concluded that: 'PPV alone induces no appreciable long-term corneal astigmatism.' Another study of 36 patients found a mean astigmatism of $2.97 \mathrm{dpt}$ immediately after the operation, declining to $0.67 \mathrm{dpt}$ at 4 months [54].

Studies of patients following $25 \mathrm{~g}$ vitrectomy have shown less astigmatism, with a mean induced astigmatism of $0.38 \mathrm{dpt}$ [55]. A prospective randomised controlled trial comparing $25 \mathrm{~g}$ and $20 \mathrm{~g}$ vitrectomy in $67 \mathrm{pa}-$ tients with macular pucker found more astigmatism immediately after the operation, but no significant difference between the 2 groups at 6 months [56]. Okamoto et al. [57] used corneal topography to examine patients having either $25 \mathrm{~g}$ or $20 \mathrm{~g}$ vitrectomy for regular astigmatism, asymmetry and higher-order irregularity. There were no changes in the $25 \mathrm{~g}$ group, but significant changes in the $20 \mathrm{~g}$ group at 2 weeks following surgery. However, these had returned to pre-operative levels at 1 month. In a more recent but small comparative study, keratometric astigmatism was found only in the $20 \mathrm{~g}$ group, but this had returned to baseline at 3 months [58].

The published studies seem to be in agreement that $25 \mathrm{~g}$ vitrectomy induces less astigmatism than $20 \mathrm{~g}$ vitrectomy. However, induced astigmatism does not appear to be a clinically significant issue following $20 \mathrm{~g}$ vitrectomy, and in any event resolves after a few months.

\section{Operating Time}

Quicker wound construction and the elimination of sutures reduces the time required for these steps when using $25 \mathrm{~g}$ techniques. In a comparative study of patients having vitrectomy for epiretinal membranes, the mean duration of surgery was $15.6 \mathrm{~min}$ (range 13-20 min) in the $25 \mathrm{~g}$ group and $29.6 \mathrm{~min}$ (range $22-35 \mathrm{~min}$ ) in the $20 \mathrm{~g}$ group [50]. In a randomised trial of 67 patients with 
epiretinal membranes, the total operating time in the $20 \mathrm{~g}$ group was $34.1 \mathrm{~min}$, as opposed to $24.3 \mathrm{~min}$ in the $25 \mathrm{~g}$ group [56]. Shinoda et al. [59] reported a comparative study in macular hole surgery with $25 \mathrm{~g}$ and $20 \mathrm{~g}$ instruments, and found that operating time was significantly shorter in the $25 \mathrm{~g}$ group $(56 \pm 16 \mathrm{~min})$ than in the $20 \mathrm{~g}$ group ( $85 \pm 28 \mathrm{~min}$ ). However, 2 other randomised studies reported no difference in total operating times between the 2 techniques, both finding that any time saved in wound opening and closure was lost because of the longer duration of vitrectomy $[20,51]$.

\section{Outcomes}

Most studies examining $25 \mathrm{~g}$ and $23 \mathrm{~g}$ outcomes have found no significant difference when compared with $20 \mathrm{~g}$ results in a wide variety of routine vitreoretinal conditions $[15,16,60]$. However, one pathology for which this might not be the case is retinal detachment [61]. Most surgeons agree that the removal of peripheral vitreous is important in the management of retinal detachment by vitrectomy, and that indentation of the periphery is helpful in locating retinal breaks. Both these steps are more difficult in 25g surgery, and there were early reports of high re-attachment rates following $25 \mathrm{~g}$ vitrectomy. In a series of 53 eyes managed by $25 \mathrm{~g}$ vitrectomy, the primary success rate was only $74 \%$, the reasons for failure being either new retinal breaks or PVR. In addition, 3 eyes $(6 \%)$ in this series developed postoperative choroidal haemorrhage [62]. The authors noted the high incidence of PVR, and suggested that the lower flow rate may leave higher concentrations of cytokines in the eye. They cautioned against the use of $25 \mathrm{~g}$ vitrectomy for retinal detachment pending further study. Other studies have reported higher success rates. A small study of $25 \mathrm{~g}$ vitrectomy in the management of non-complex pseudophakic retinal detachments reported primary success in all but 1 case [63]. More recent studies have reported reasonable success rates (primary success $92.9 \%$ ) for $25 \mathrm{~g}$ vitrectomy and gas without the use of a supplementary buckle [64].

\section{3g Vitrectomy}

One inevitable consequence of using $25 \mathrm{~g}$ instruments is a reduction in stiffness of the instruments. This makes rotating the globe in order to access the peripheral vitreous difficult. Frustrated with this and other shortcom- ings of 25g vitrectomy, Eckardt [65] developed a method of transconjunctival sutureless vitrectomy using $23 \mathrm{~g}$ instruments through shelved transconjunctival incisions. He used a 2-stage procedure where an incision was made with a $23 \mathrm{~g}$ blade, followed by insertion of the cannulas using a separate instrument while maintaining the relative position of the conjunctiva and underlying sclera. He reported on 41 eyes undergoing this procedure. None of the sclerotomies required suturing and no hypotony was reported, though there were some cases of vitreous cavity haemorrhage from the entry sites. The method had several advantages, including the use of pre-existing instrumentation. The stiffness of the cutter is similar to a $20 \mathrm{~g}$ instrument, making rotation of the globe during vitrectomy easier. In addition, the shelved incisions were self-sealing, reducing the incidence of leaking wounds and hypotony. Early experience has suggested that the technique is more practical, and there are suggestions that it is associated with a lower rate of complications [66].

In a comparative study of 100 eyes undergoing surgery for epiretinal membrane, there was no significant difference in post-operative IOP between the $20 \mathrm{~g}$ group and the $25 \mathrm{~g}$ group [66]. This may be related to the shelved incisions which are an essential component of the technique with $23 \mathrm{~g}$ surgery. In another retrospective study examining $23 \mathrm{~g}$ vitrectomy in 77 eyes, hypotony occurred in only 2 patients on postoperative day 1 , with only 1 patient requiring a sclerotomy suture [67].

There have been fewer reports of endophthalmitis following $23 \mathrm{~g}$ surgery, although the technique is more recent and is currently less widely used than $25 \mathrm{~g}$ surgery. However, in one large series of 943 cases of $23 \mathrm{~g}$ vitrectomy, there were no cases of endophthalmitis reported [68].

\section{Recent Developments in 20g Vitrectomy}

The benefits in terms of patient comfort associated with $23 \mathrm{~g}$ and $25 \mathrm{~g}$ systems have stimulated some surgeons into making improvements to conventional $20 \mathrm{~g}$ vitrectomy techniques. Lafeta and Claes [69] introduced a sutureless cannula system for $20 \mathrm{~g}$ instruments, incorporating a valve to prevent a reduction in IOP during instrument exchanges. In a series of 50 eyes with routine pathology, there were no significant complications reported. However, in another study of this technique, the larger wounds required a suture to close them in 38\% of cases [70]. 
Gotzaridis [71] has advocated a technique where cautery is used to fix the conjunctival to the underlying sclera. An angled incision is then fashioned using an MVR blade. Following 20g vitrectomy, only 3 out of 84 eyes $(5 \%)$ had hypotony on day 1 , and in all cases this improved by the third post-operative day. Two of the cases had a bleb formation and the remainder minor leakage through the flat conjunctiva.

Based on the assumption that post-operative patient comfort is related to exposed sutures, Zhao et al. [72] have suggested a technique of $20 \mathrm{~g}$ vitrectomy through small radially-orientated conjunctival incisions. The sclerotomies are sutured at the end of surgery using a buried finewire suture, but it is not necessary to close the conjunctiva.

Thinking along similar lines, David Williams [pers. commun.] proposed a minor modification to conventional $20 \mathrm{~g}$ vitrectomy using a single superior conjunctival flap, and placing the infusion port at 12 o'clock. This has the advantage of requiring only a single exposed conjunctival suture, but also confining all the wounds to the area under the upper lid, considerably improving post-operative appearance and comfort.

\section{Summary}

The introduction of truly sutureless vitrectomy systems (starting with $25 \mathrm{~g}$ transconjunctival vitrectomy) has stimulated a great deal of interest, and such systems have gained wide adoption in many centres. The benefits from the patient's point of view seem to be reduced postoperative discomfort, and faster visual rehabilitation, but these relatively minor benefits need to be balanced against the possible increased risk of complications. Where that balance lies remains an open question, and more prospective randomised controlled trials are required, so that the risk and benefits can be more accurately characterised.

Once the patient benefits are clear, then the issue of cost-benefit also requires attention, and this is an issue which is of major concern in most healthcare systems. In one large teaching centre, the cost of sutureless microincision vitrectomy surgery was calculated to be 3.4 times higher than that of sutured $20 \mathrm{~g}$ vitrectomy surgery [73]. While shorter surgery times have the potential to reduce costs, this has to be set against the higher cost of sutureless systems, and the considerable investment that has already been made in $20 \mathrm{~g}$ instruments in many centres.

\section{References}

1 Illiff CE: Treatment of the vitreous-tug syndrome. Am J Ophthalmol 1966;66:856-859.

2 Kasner D: Vitrectomy: a new approach to management of vitreous. Highlights Ophthalmol 1969;11:304.

$\checkmark 3$ Machemer R, Buettner H, Norton EWD, Parel JM: Vitrectomy: a pars plana approach. Trans Am Acad Ophthalmol Otolaryngol 1971;75:813.

4 O'Malley C, Heintz RM: Vitrectomy with an alternative instrument system. Ann Ophthalmol 1975;7:585-594.

5 Machemer R, Hickingbotham D: The threeport microcannular system for closed vitrectomy. Am J Ophthalmol 1985;100:590-592.

$\checkmark 6$ Hilton GF: A sutureless self-retaining infusion cannula for pars plana vitrectomy. Am J Ophthalmol 1985;99:612.

7 Mason G, Sullivan JM, Olk RJ: A sutureless self-retaining infusion cannula for pars plana vitrectomy. Am J Ophthalmol 1990;110: 577-578.

$\checkmark 8$ Chen JC: Sutureless pars plana vitrectomy through self-sealing sclerotomies. Arch Ophthalmol 1996;114:1273-1275.

9 Milibak T, Suveges I: Complications of sutureless pars plana vitrectomy through selfsealing sclerotomies. Arch Ophthalmol 1998;116:119.
10 Rahman R, Rosen PH, Riddell C, Towler H: Self-sealing sclerotomies for sutureless pars plana vitrectomy. Ophthalmic Surg Lasers 2000;31:462-466.

$\checkmark 11$ Kwok AK, Tham CC, Lam DS, Li M, Chen JC: Modified sutureless sclerotomies in pars plana vitrectomy. Am J Ophthalmol 1999; 127:731-733.

$>12$ Jackson T: Modified sutureless sclerotomies in pars plana vitrectomy. Am J Ophthalmol 2000;129:116-117.

-13 Assi AC, Scott RAH, Charteris DG: Reversed self-sealing pars plana sclerotomies. Retina 2000;20:689-692.

-14 Fujii GY, De Juan E, Humayun MS, et al: The new 25 gauge instrument system for transconjunctival sutureless vitrectomy surgery. Ophthalmol 2002;109:1807-1812.

15 Fujii GY, De Juan E, Humayun MS, et al: Initial experience using the transconjunctival sutureless vitrectomy system for vitreoretinal surgery. Ophthalmol 2002;109:18141820 .

16 Ibarra MS, Hermel M, Prenner JL, Hassan TS: Longer-term outcomes of transconjunctival sutureless 25-gauge vitrectomy. Am J Ophthalmol 2005;139:831-836.
17 Lakhanpal RR, Humayun MS, de Juan E Jr, et al: Outcomes of 140 consecutive cases of 25-gauge transconjunctival surgery for posterior segment disease. Ophthalmol 2005; 112:817-824.

18 Shimada H, Nakashizuka H, Mori R, Mizutani Y: Expanded indications for 25-gauge transconjunctival vitrectomy. Jpn J Ophthalmol 2005;49:397-401.

19 Shah CP, Ho AC, Regillo CD, Fineman MS, Vander JF, Brown GC: Short-term outcomes of 25-gauge vitrectomy with silicone oil for repair of complicated retinal detachment. Retina 2008;28:723-728.

20 Kellner L, Wimpissinger B, Stolba U, Brannath $\mathrm{W}$, Binder S: 25 gauge versus 20 gauge system for pars plana vitrectomy: a prospective randomized clinical trial. Br J Ophthalmol 2007;91:945-948.

21 Inoue M, Noda K, Ishida, S, Nagai N, Imamura Y, Oguchi Y: Intraoperative breakage of a 25-gauge vitreous cutter. Am J Ophthalmol 2004;138:867-869.

22 Cohen SM, Flynn HW, Murray TG, Smiddy WE: Endophthalmitis after pars plana vitrectomy. The Postvitrectomy Endophthalmitis Study Group. Ophthalmol 1995;102: 705-712. 
23 Eifrig CW, Scott IU, Flynn HW, et al: Endophthalmitis after pars plana vitrectomy: incidence, causative organisms, and visual acuity outcomes. Am J Ophthalmol 2004; 138:799-802.

-24 Taylor SR, Aylward GW: Endophthalmitis following 25-gauge vitrectomy. Eye 2005;19: 1228-1229.

-25 Kunimoto DY, Kaiser RS: Incidence of endophthalmitis after 20- and 25-gauge vitrectomy. Ophthalmol 2007;114:2133-2137.

26 Martidis A, Chang TS: Sutureless 25-gauge vitrectomy: risky or rewarding? Ophthalmol 2007;114:2131-2132.

-27 Taban M, Ufret-Vincenty RL, Sears JE: Endophthalmitis after 25-gauge transconjunctival sutureless vitrectomy. Retina 2006;26: 830-831.

$\checkmark 28$ Scott IU, Flynn HW Jr, Dev S, et al: Endophthalmitis after 25-gauge and 20-gauge pars plana vitrectomy: incidence and outcomes. Retina 2008;28:138-142.

-29 Shimada H, Nakashizuka H, Hattori T, Mori R, Mizutani Y, Yuzawa M: Incidence of Endophthalmitis after 20- and 25-gauge vitrectomy. Ophthalmol 2008;115:22152220.

30 Mason JO III, Yunker JJ, Vail RS, et al: Incidence of endophthalmitis following 20gauge and 25-gauge vitrectomy. Retina 2008; 28:1352-1354.

- 31 Acar N, Unver YB, Altan T, Kapran Z: Acute endophthalmitis after 25-gauge sutureless vitrectomy. Int Ophthalmol 2007;27:361363.

- 32 Acar N, Kapran Z, Unver Y, Altan T Ozdogan S: Early postoperative hypotony after 25-gauge sutureless vitrectomy with straight incisions. Retina 2008;28:545-552.

- 33 Lommatzsch A, Heimes B, Trieschmann M, Spital G, Pauleikhoff D: Long-term results after pars plana vitrectomy with 25 gauge technique. Ophthalmologe 2008; 105:445451.

-34 Rezende FA, Regis LGT, Kickinger M, Alcantara S: Decompression retinopathy after 25 -gauge transconjunctival sutureless vitrectomy: report of 2 cases. Arch Ophthalmol 2007;125:699-700.

- 35 Amato JE, Akduman L: Incidence of complications in 25-gauge transconjunctival sutureless vitrectomy based on the surgical indications. Ophthalmic Surg Lasers Imaging 2007:38:100-102.

- 36 Cardascia N, Boscia F, Furino C, Sborgia L: Gentamicin-induced macular infarction in transconjunctival sutureless 25 -gauge vitrectomy. Int Ophthalmol 2008:28:383-385.

-37 Lopez-Guajardo L, Vleming-Pinilla E, Pareja-Esteban J, Teus-Guezala MA: Ultrasound biomicroscopy study of direct and oblique 25-gauge vitrectomy sclerotomies. Am J Ophthalmol 2007; 143:881-883.

- 38 Riemann CD, Miller DM, Foster RE, Petersen MR: Outcomes of transconjunctival sutureless 25-gauge vitrectomy with silicone oil infusion. Retina 2007;27:296-303.
39 Gupta OP, Weichel ED, Regillo CD, Fineman MS, Kaiser RS, Ho AC, McNamara JA, Vander JE: Postoperative complications associated with 25 -gauge pars plana vitrectomy. Ophthalmic Surg Lasers Imaging 2007; 38:270-275

40 Batman C, Ozdamar Y, Aslan O, Sonmez K, Mutevelli S, Zilelioglu G: Tissue glue in sutureless vitreoretinal surgery for the treatment of wound leakage. Ophthalmic Surg Lasers Imaging 2008;39:100-106.

41 Lopez-Guajardo L, Pareja-Esteban J, TeusGuezala M: Oblique sclerotomy technique for prevention of incompetent wound closure in transconjunctival 25-gauge vitrectomy. Am J Ophthalmol 2006;141:11541156.

42 Hsu J, Chen E, Gupta O, Fineman MS, Garg SJ, Regillo CD: Hypotony after 25-gauge vitrectomy using oblique versus direct cannula insertions in fluid-filled eyes. Retina 2008; 28:937-940

43 Shimada H, Nakashizuka H, Mori R, Mizutani Y, Hattori T: 25-gauge scleral tunnel transconjunctival vitrectomy. Am J Ophthalmol 2006;142:871-873.

44 Singh RP, Bando H, Brasil OFM, Williams DR, Kaiser PK: Evaluation of wound closure using different incision techniques with 23-gauge and 25 -gauge microincision vitrectomy systems. Retina 2008;28:242-248.

45 Scartozzi R, Bessa AS, Gupta OP, Regillo CD: Intraoperative sclerotomy-related retinal breaks for macular surgery, 20-vs 25-gauge vitrectomy systems. Am J Ophthalmol 2007; 143:155-156.

46 Okuda T, Nishimura A, Kobayashi A, Sugiyama K: Postoperative retinal break after 25 -gauge transconjunctival sutureless vitrectomy: report of four cases. Graefes Arch Clin Exp Ophthalmol 2007;245:155-157.

47 Tan HS, Mura M, de Smet MD: Iatrogenic retinal breaks in 25-gauge macular surgery. Am J Ophthalmol 2009;148:427-430.

48 Park SS, Marcus DM, Duker JS, et al: Posterior segment complications after vitrectomy for macular hole. Ophthalmology 1995;102: 775-781.

49 Byeon SH, Chu YK, Lee SC, Koh HJ, Kim SS, Kwon OW: Problems associated with the 25 -gauge transconjunctival sutureless vitrectomy system during and after surgery. Ophthalmologica 2006;220:259-265.

50 Rizzo S, Genovesi-Ebert F, Murri F, Belting C, Vento A, Cresti F, Manca ML: 25-gauge, sutureless vitrectomy and standard 20 -gauge pars plana vitrectomy in idiopathic epiretinal membrane surgery: a comparative pilot study. Graefes Arch Clin Exp Ophthalmol 2006;244:472-479.

51 Wickham L, Bunce CS, Kwan AS, Bainbridge JW, Aylward B: A pilot randomised controlled trial comparing the post-operative pain experience following vitrectomy with a 20 -gauge system and the 25-gauge transconjunctival system. Br J Ophthalmol 2009, E-pub ahead of print.
52 Jampel HD, Thompson JT, Nunez M, Michels RG: Corneal astigmatic changes after pars plana vitrectomy. Retina 1987;7:223226.

53 Eckert T, Eckardt C: Outcome of corneal astigmatism after pars plana vitrectomy with or without simultaneous cataract extraction. Ophthalmologe 1996;93:38-44.

54 Wirbelauer C, Hoerauf H, Roider J, Laqua H: Corneal shape changes after pars plana vitrectomy. Graefes Arch for Clini Exp Ophthalmol 1998;236:822-828.

55 Yanyali A, Celik E, Horozoglu F, Nohutcu AF: Corneal topographic changes after transconjunctival (25-gauge) sutureless vitrectomy. Am J Ophthalmol 2005;140:939941.

56 Kadonosono K, Yamakawa T, Uchio E, Yanagi Y, Tamaki Y, Araie M: Comparison of visual function after epiretinal membrane removal by 20 -gauge and 25 -gauge vitrectomy. Am J Ophthalmol 2006;142: 513-515.

57 Okamoto F, Okamoto C, Sakata N, Hiratsuka K, Yamane N, Hiraoka T, Kaji Y, Oshika $\mathrm{T}$ : Changes in corneal topography after 25 -gauge transconjunctival sutureless vitrectomy versus after 20 -gauge standard vitrectomy. Ophthalmol 2007;114:2138-2141.

58 Citirik M, Batman C, Bicer T, Zilelioglu O: Keratometric alterations following the 25 -gauge transconjunctival sutureless pars plana vitrectomy versus the conventional pars plana vitrectomy. Clin Exp Optometry 2009;92:416-420

-59 Shinoda H, Nakajima T, Shinoda K, et al: Visual recovery after vitrectomy for macular hole using 25-gauge instruments. Acta Ophthalmol 2008;86:151-155.

-60 Guyomarch J, Delyfer MN, Korobelnik JF: Outcomes of 110 consecutive 25-gauge transconjunctival sutureless pars plana vitrectomies (in French). J Fr Opthalmol 2008; 31:473-480.

61 Heimann H: Primary 25- and 23-gauge vitrectomy in the treatment of rhegmatogenous retinal detachment - advancement of surgical technique or erroneous trend? Klin Monats Augen 2008;225:947-956.

62 Lai MM, Runby AJ, Sarrafizadeh R, Urban KE, Hassan TS, Drenser KA, Garretson BR: Repair of primary rhegmatogenous retinal detachment using 25-gauge transconjunctival sutureless vitrectomy. Retina 2008;28: 729-734.

63 Acar N, Kapran Z, Altan T, Unver Y, Yurtsever S, Kucuksumer Y: Primary 25-gauge sutureless vitrectomy with oblique sclerotomies in pseudophakic retinal detachment. Retina 2008:28:1068-1074.

64 Miller DM, Riemann CD, Foster RE, Petersen MR: Primary repair of retinal detachment with 25-gauge pars plana vitrectomy. Retina 2008;28:931-936.

-65 Eckardt C: Transconjunctival sutureless 23-gauge vitrectomy. Retina 2005;25:208211. 
-66 Hikichi T, Matsumoto N, Ohtsuka H, Higuchi M, Matsushita T, Ariga H, Kosaka S, Matsushita R: Comparison of one-year outcomes between 23- and 20-gauge vitrectomy for preretinal membrane. Am J Ophthalmol 2009; 147:639-643.

67 Fine HF, Iranmanesh R, Iturralde D, Spaide RF: Outcomes of 77 consecutive cases of 23-gauge transconjunctival vitrectomy surgery for posterior segment disease. Ophthalmol 2007;114:1197-1200.
68 Parolini B, Romanelli F, Prigione G, Pertile $\mathrm{G}$ : Incidence of endophthalmitis in a large series of 23-gauge and 20-gauge transconjunctival pars plana vitrectomy. Graefes Arch Clin Exp Ophthalmol 2009:247:895898.

69 Lafeta, AP, Claes C: Twenty-gauge transconjunctival sutureless vitrectomy trocar system. Retina 2007;27:1136-1141.

70 Kim JE, Shah SN, Choi DL, Han DP, Connor TB: Transconjunctival 20-gauge pars plana vitrectomy using a single entry cannulated sutureless system. Retina 2009;29:12941298.
71 Gotzaridis EV: Sutureless transconjunctival 20 gauge pars plana vitrectomy. Semin Ophthalmol 2007;22:179-183.

72 Zhao M, Zhou P, Xuan C, Wang Y, Li X: Manual small incision 20-gauge pars plana vitrectomy. Retina 2009;29:1364-1366.

73 Lewis H: Sutureless microincision vitrectomy surgery: unclear benefit, uncertain safety. Am J Ophthalmol 2007;144:613-615. 